\title{
Developing alternative business models for smart infrastructure: a UK case study
}

Chris J. Bouch BSC, MSc, CEng, MICE, MINCOSE Senior Research Fellow, School of Engineering, University of Birmingham, Birmingham, UK (corresponding author: c.bouch@bham.ac.uk)

Chris D. F. Rogers Eur Ing, BSC, PhD, CEng, MICE, MCIHT Professor of Geotechnical Engineering and Director, UKCRIC National Buried Infrastructure Facility, School of Engineering, University of Birmingham, Birmingham, UK
Mark J. Powell BA, PhD

Researcher, Centre for Earth Systems Engineering Research, University of Newcastle, Newcastle, UK

David A. C. Horsfall BSC, MRICS, ARTPI

Director DACH Planning, Non-executive Director, Webster and Horsfall Holdings Ltd, Birmingham, UK

There is a need to identify as wide a range as possible of sources of value arising from a given infrastructure development when creating infrastructure business models. The need for novel, more effective business models is being driven by the UK government's very considerable programme of infrastructure investment, coupled with a reduction in the supply of public capital over recent years and a corresponding increase in the demand for private project finance. To support both public and private infrastructure investment, new business models are required that can internalise the positive externalities associated with public goods. Based on an exploration of the application of soft systems methodology to business model creation, this paper proposes a generic six-step methodology for identifying a wide range of potentially value-generating opportunities and proves its efficacy by applying it to a case study of Tyseley Energy Park in Birmingham, UK. The findings from the methodology, which treats a newly constructed, refurbished or upgraded infrastructure system as a 'business', can then be used to broker the necessary collaboration with all relevant stakeholders - those who have a stake in the business - to refine the business models and ensure that they are resilient in the face of contextual change.

\section{Introduction}

This paper focuses on research into the development of a generic methodology for identifying as wide a range as possible of potential value-generating opportunities for a given infrastructure development as an essential step in the process of creating novel, more effective infrastructure business models. Its efficacy is demonstrated by way of a case study based on Tyseley Energy Park (TEP) in Birmingham, UK - an ambitious new development of colocated energy and other cognate businesses - yet the methodology can be applied in principle to any substantial intervention in the infrastructure systems that support society: the creation of a single new infrastructure artefact, refurbishment or upgrading of an infrastructure artefact or a fundamental change to an infrastructure operating system. Importantly, the infrastructure thus developed is treated as a business in the creation of alternative business models that might support it. This work is part of the Engineering and Physical Sciences Research Council (EPSRC) and Economic and Social Research Council (ESRC)-funded infrastructure BUsiness models, valuation and Innovation for Local Delivery (iBUILD) project's research into the application of soft systems methodology (SSM) to the creation of infrastructure business models that aim to increase value capture for investors, thereby supporting public and private investment in new, and increasingly smart, infrastructure.

When considered in the light of services to individuals and communities, the concept of infrastructure should not be confined to transport, water, waste management, energy and information and communication technology (ICT). It should extend to a range of social infrastructures, including health, education, culture and green and blue spaces, among others. Dawson (2013) analysed published literature to produce the following holistic definition of infrastructure: 'The artefacts and processes of the inter-related systems that enable the movement of resources in order to provide the services that mediate (and ideally enhance) security, health, economic growth and quality of life at a range of scales' (Dawson, 2013: p. 4). Implicit in this are the links between infrastructures and the wider environment in which they are situated, which offer opportunities for infrastructure to be smarter and generate a wider range of value than that provided solely from an infrastructure's main purpose - for example, the provision of electricity.

Similarly, smart infrastructure is not just about using data to make civilised life more efficient - and given that the majority of people now live in urban areas, the term 'cities' is used in this paper as shorthand for where infrastructure systems focus their impacts, whether within or connecting cities and other communities. It is an essential contributor to, and driver of, cities and city systems that deliver value (economic, social, cultural and environmental) to their inhabitants in terms of sustainability, resilience, adaptability, liveability, systems integration, local relevance, innovation, economic viability, appropriate skill base and the necessary governance/regulatory structures and processes (IEC, 2014; Rogers, 2018; UNCSTD, 2016). In this paper, the term 'smart infrastructure' is used in this broad, holistic context that is, 'smart infrastructure' is 'smart' only if it delivers on these wider agendas (Cavada et al., 2014, 2016).

The UK government is planning to invest more than $£ 400$ billion in infrastructure, with around half of that coming from private investors, and $£ 300$ billion is scheduled for delivery by 2021 (IPA, 2016). This 
strategy stems from recognition that over several decades investment in the country's infrastructure generally has been '... timid, uncoordinated, incremental, wasteful in its procurement and insufficiently targeted to supporting balanced and sustainable growth in the economy, both economically and environmentally' (HMT, 2010: p. 3). Future investment will be taking place at a time of change in the UK's infrastructure. The current paradigm, one of large-scale, centralised facilities such as power stations and water distribution networks (Egyedi and Mehos, 2012), is shifting towards smaller-scale, locally controlled facilities (KPMG, 2017). This trend is particularly visible in the field of energy, where smart distributed energy infrastructure is characterised by '... more diverse, dynamic, and complex systems with multiple actors and multi-layered energy, information, and money flows' (Siemens, 2018: p. 5).

Traditionally, governments have used public funds to finance infrastructure investments, which were seen as public goods providing positive externalities (OECD, 2014). A pure public good is one that is non-excludable (it is not possible to exclude people from using it even if they have not paid) and non-rival (one person's use is not diminished when other people use it); a classic example is defence of national borders. However, pure public goods are few and far between, and some goods and services considered as public have neither non-excludable nor non-rival attributes. Instead, they are regarded as public on the strength of their positive externalities - that is, they provide benefits to society that are not priced into the good or service itself (Bartlett, 2017). An example might be a plant for the generation of green energy: this is not strictly a public good because one normally has to pay for use of the energy produced, but there is potentially a positive externality in the form of improved air quality for residents in areas that would otherwise be impacted by the adverse effects of energy generation.

Over recent years, however, funding and financing of infrastructure have been changing, with a strong reduction in the supply of public capital and a move towards project finance (OECD, 2014). The decline in public capital has been driven by '... public deficits, increased public debt to GDP ratios and, sometimes, the inability of the public sector to deliver efficient investment spending and misallocations of resources due to political interferences' (OECD, 2014: p. 6). The rise in project finance, on the other hand, has been based on '.. lenders and investors (relying) either exclusively ("non-recourse" financing) or mainly ("limited recourse" financing) on the cash flow generated by the project to repay their loans and earn a return on their investments' (EIB, 2011: p. 47). Inherent in this debate is the wider perspective on investment introduced, for example, by the 'five capitals' model (financial capital, manufactured capital, human capital, social capital and natural capital (Porritt, 2005)). While this does not alter the need for a business to be economically viable, it makes room for considerations of additionality.

The move to project financing makes it important to find new business models that can maximise value capture for public and private investors - including through the internalisation of positive externalities - to improve cash flow and encourage investment. The process of creating the new business models must be sufficiently dynamic to cope with the constant stream of technological, policy and regulatory developments, as well as ongoing environmental trends and drivers that organisations face (Burger and Luke, 2016). It must take account of the social aspects of an organisation's operations and provide a more accurate representation of the actual processes of organisational transformation, involved in establishing and maintaining business models across a network of stakeholders (Randles and Laasch, 2016). Moreover, it must have a temporal element, telling the story of how an organisation's operations have developed - 'A good business model begins with [a narrative around] human motivations and ends in a rich stream of profits' (Magretta, 2002: p. 3).

The iBUILD project (Dawson et al., 2014) has been researching the ability of SSM to help entrepreneurs cope with the complex and dynamic problem of developing new business models for smart infrastructure. Often attributed to Checkland, SSM recognises that solution-oriented, design-science approaches to management problems such as business model creation are not appropriate. Instead, it employs an iterative, self-reflective learning process, where each cycle produces a better understanding of the problem and assists towards a 'solution' that can accommodate the different perspectives of the various stakeholders in a systemically desirable and culturally feasible way (Checkland and Scholes, 1999). In effect, with SSM, one never stops learning about the problem at hand and the potential solutions - an approach that would seem well placed to help businesses cope with the dynamism surrounding business models.

This paper addresses stage 1 of SSM, which Checkland dubbed the 'finding out phase' (Checkland and Scholes, 1999: p. 66): establishing the historical, physical, political, economic and social context within which the new business model will be built. In particular, the paper focuses on research into the development of a generic methodology for identifying as wide a range as possible of potentially value-generating opportunities for a given infrastructure development, which could be internalised within a new business model to support both public and private investment. The paper illustrates the research using a case study based on TEP, an integrated, distributed energy facility under development in the Tyseley area of Birmingham, UK (WHHL, 2018). As currently envisaged, TEP will comprise a number of separate businesses, each with their own business model. However, to maximise the value generated by TEP, there is an aspiration for the businesses to form links both between one another and with their wider environment over time and develop synergies that will enhance value creation. With this in mind, iBUILD has been researching the feasibility of creating an overarching business model for TEP to help steer its development into the future.

The following sections of this paper provide an overview of TEP and SSM, before going on to describe the generic methodology 
Smart Infrastructure and Construction

Volume 171 Issue SC2
Developing alternative business models

for smart infrastructure: a UK case study

Bouch, Rogers, Powell and Horsfall for identifying as wide a range as possible of potentially valuegenerating opportunities in the context of TEP. The results obtained from applying the methodology to TEP are presented and discussed. Finally, conclusions are drawn, and plans for future research outlined.

\section{Tyseley Energy Park (TEP)}

TEP is an integrated, distributed energy facility that is emerging on an industrial site in the Tyseley area of Birmingham, UK (Figure 1). The site is owned by Webster and Horsfall Limited (WHHL), who have been operating their wire-drawing business from there since 1848 . In the late 1990s/early 2000s, they made the strategic decision to concentrate on the manufacture of wires for specialist applications, which required a smaller operational footprint, thus releasing 10 acres $(4.04 \mathrm{ha})$ of land for redevelopment. As a family-owned company, the board of directors of WHHL decided that developing TEP would allow the company to continue its long-standing association with the Tyseley area, providing the people living there with employment and economic security and enhancing natural and social capital while at the same time helping to secure the longer-term future of the wire drawing business.

The vision for TEP is shown in Figure 2, although it should be noted that the diagram does not provide a true representation of where each business/organisation will ultimately be located. Already on-site is a $10 \mathrm{MW}$ biomass plant, gasifying up to $80000 \mathrm{t}$ of wood waste per annum. The gas powers turbines supplying power to the National Grid and, by way of 'private-wire' agreements, to the operations of WHHL and Rent-E, a company renting electric taxis to Uber drivers. At the time of writing, work is under way on the construction of green-fuel (compressed natural gas, hydrogen, electricity and biodiesel) vehicle-refuelling facilities. In conjunction with that, a hydrogen electrolyser is being set up, which will use low-cost, green electricity from the biomass plant to generate hydrogen, while Fraunhofer Umsicht will be trialling a prototype thermal catalytic reformer, which will produce biodiesel from a variety of waste types. Another recent development has been a $£ 2.5$ million investment in the site by the University of Birmingham, which '... intends to develop skills and training within TEP, together with collaborative research and development of manufacturing, to help companies successfully engage with the revolution that is happening in transport, energy and the circular economy' (UoB, 2018).

The development of TEP is building on a number of existing energy-related policies, strategies and developments. One is the initiation in 2012 by the Birmingham City Council (BCC) of the Tyseley Environmental Enterprise District (BCC, 2012), within which TEP is situated, which aims to leverage the city's existing expertise in renewable energy and energy from waste as well as further its plans to develop an integrated (green) transport infrastructure. Another is the contribution that BCC and the region's universities are making in the fields of bioenergy, hydrogen and other future power systems. Additionally, there are contributions from

- Energy Capital, the smart energy innovation partnership for the West Midlands, who are developing an 'energy innovation zone' at Tyseley (Energy Capital, 2018), which will include TEP

- the Greater Birmingham and Solihull Local Enterprise Partnership (GBSLEP) with its strategy for growth, which majors in low-carbon dioxide energy (GBSLEP, 2013)

- the new West Midlands Combined Authority, which has the responsibility for transport and housing, both of which have a strong energy interface (GBSLEP, 2013)

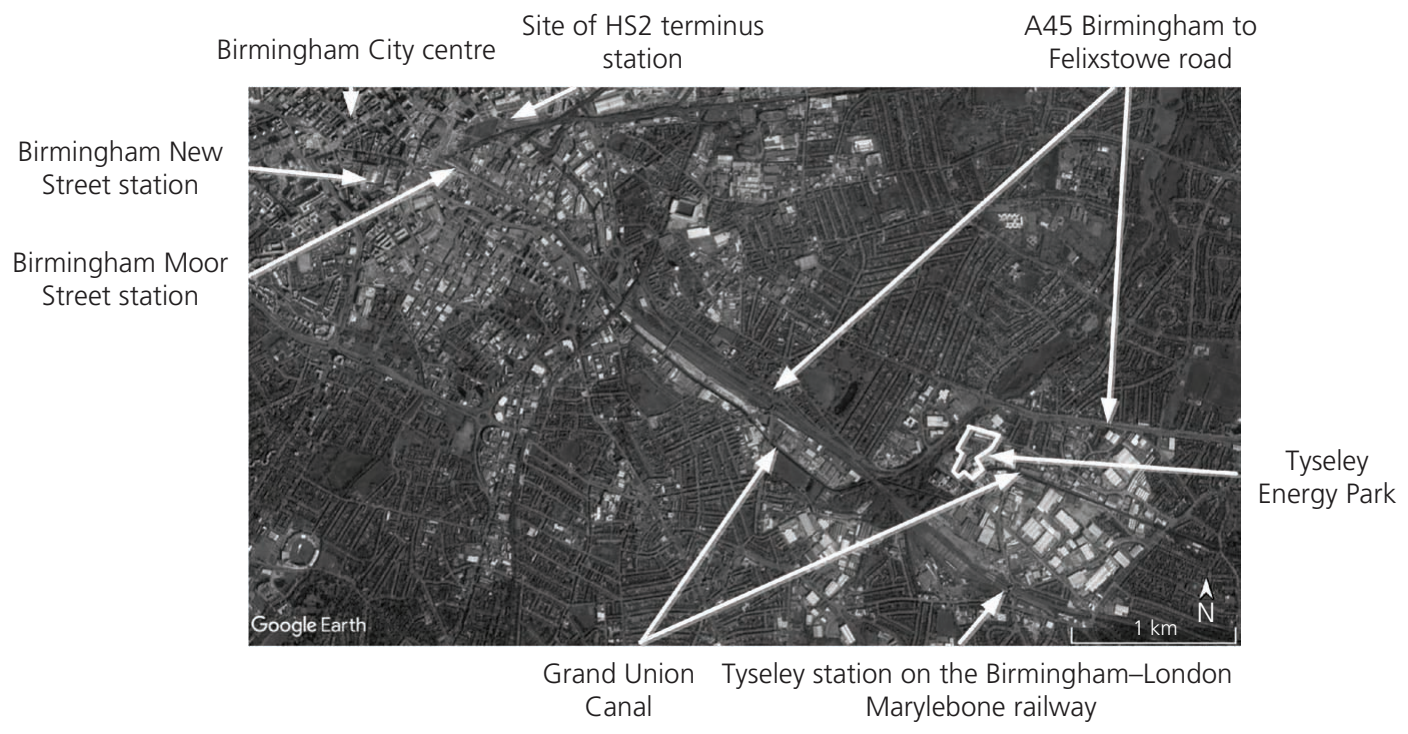

Figure 1. Plan showing the location of TEP (base map courtesy of Google Earth) 


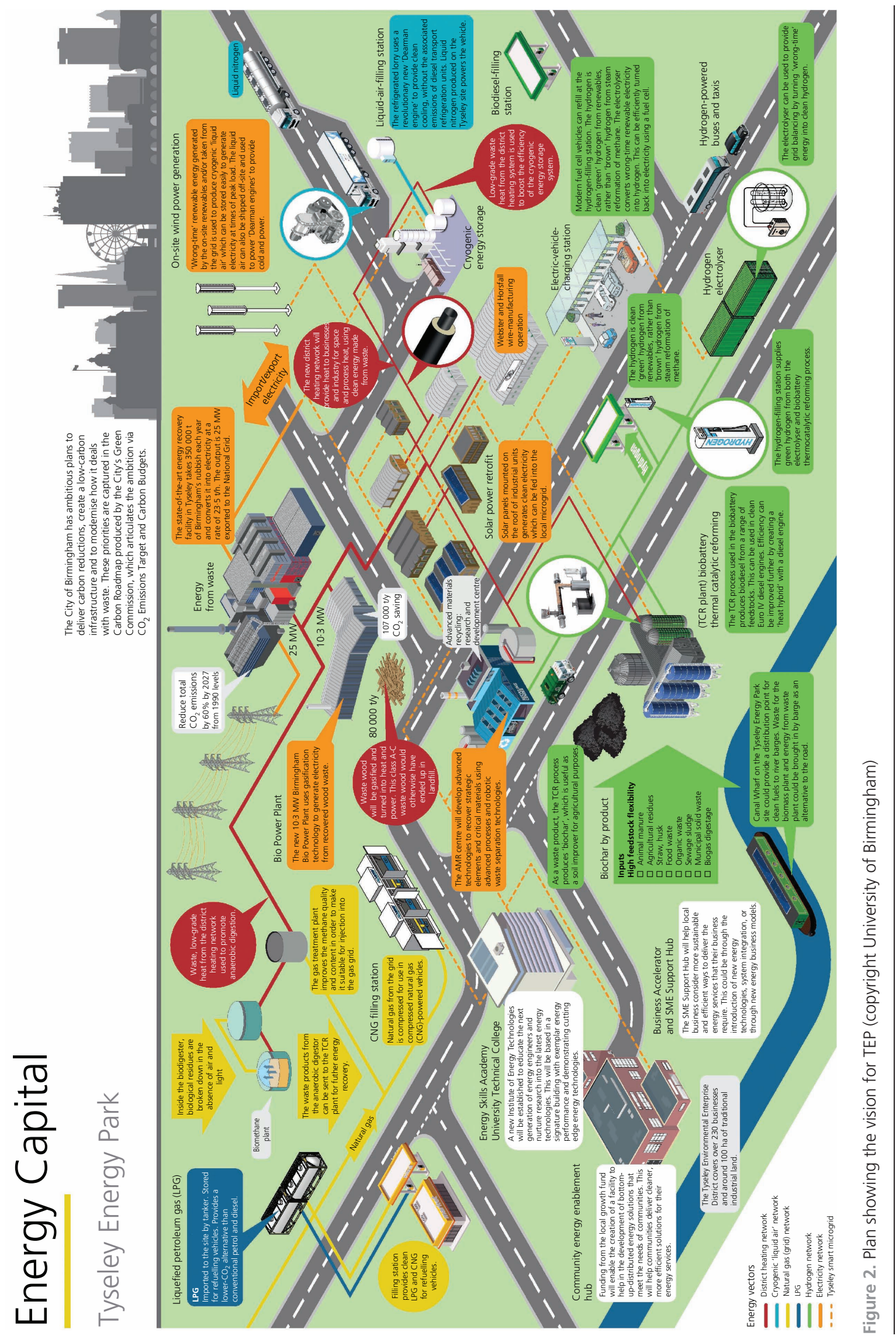


- the 'Midlands Engine', the West Midlands' version of the 'Northern Powerhouse', which is seeking to drive the innovation that will be an important part of developing Birmingham's energy businesses (Midlands Engine, 2018).

\section{Soft systems methodology (SSM)}

SSM falls under the broad heading of 'systems thinking' and was developed from 1969 onwards by Peter Checkland and colleagues at the University of Lancaster, initially in the Department of Systems Engineering and latterly in the Department of Management Science. Checkland's research programme sought new ways of dealing with problems that managers frequently face - for example, situations that are ill-defined, subject to multiple interpretations and never static (University of Lancaster, 2018). SSM stemmed from Checkland's realisation that the normal scientific method was inadequate as a way of enquiring into human situations; systems thinking in general, and SSM in particular, can be seen as a holistic reaction against the reductionism of natural science. This does not mean that SSM rejects the rigour of the scientific approach; rather, SSM can be seen as a rigorous approach to the subjectivity surrounding human affairs. SSM is a process of social enquiry aimed at improving areas of concern by means of a learning cycle that can lead to action. In support of this, it defines social reality as '... the everchanging outcome of the social process in which human beings, the product of their genetic inheritance and previous experiences, continually negotiate and re-negotiate with others their perceptions and interpretations of the world outside themselves' (Checkland and Scholes, 1999: p. 311).

SSM can be visualised as shown in Figure 3 and is described herein in the context of developing TEP's overarching business model. The process starts by assembling a comprehensive understanding of the real-world situation of concern. This will

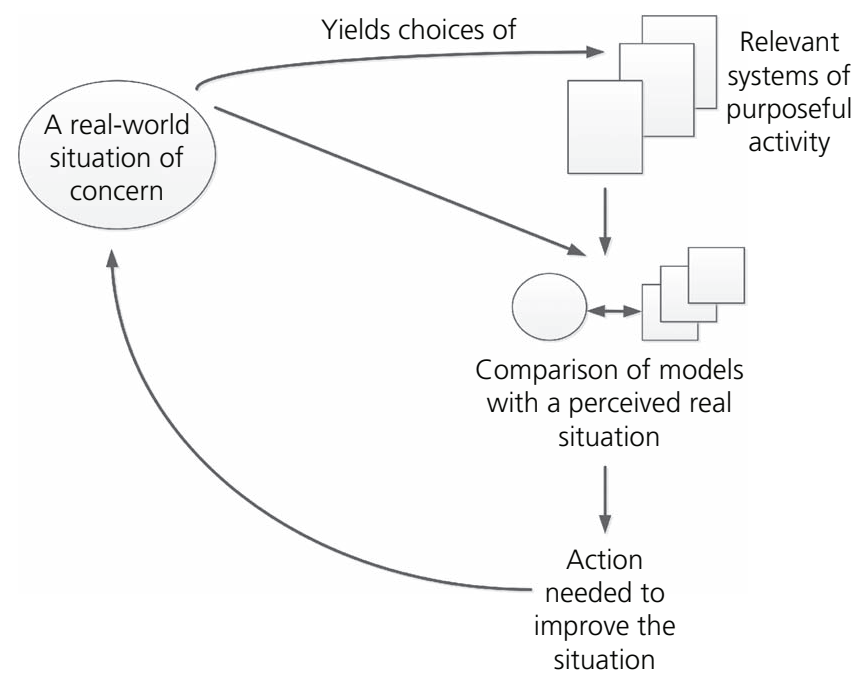

Figure 3. A simplified depiction of SSM (adapted from Checkland and Scholes (1999)) include the complex legal, policy, strategy, technology, economic and social and cultural background to integrated, distributed energy; the potential opportunities for value generation and a clear statement of the problem situation. In light of this, stakeholders will be identified who will then work on the creation of relevant systems of purposeful activity - that is, simple models consisting of a linked set of activities that aim to improve matters. It is important to note that these models do not represent the real world; rather, they are accounts of concepts of pure, purposeful activity, based on declared world views of the stakeholders, which can be used to stimulate questions in the debate about the real situation and the desirable changes to it. The models will then be compared with the real-world situation with the aim of initiating debate leading to a decision on what purposeful action to take towards creation of the overarching business model. Perhaps most importantly, the comparison will address whether the proposed actions are both systemically desirable - in other words, will they result in an improvement when viewed in the context of the existing real-world system? - and culturally feasible - in other words, given the existing culture and disposition of power among the stakeholders, can the proposed changes actually be made? (Checkland and Scholes, 1999).

The focus of each stakeholder model is referred to as the "root definition' and is expressed as a transformation process - for example, do $\mathrm{P}$ (the transformation) to $\mathrm{Q}$ (the input) in order to contribute to achieving $\mathrm{R}$ (the desired outcome). In the case of TEP, it seems likely that the desire to develop an overarching business model will be too big a step to achieve in one go; instead, WHHL and other principal stakeholders will have to decompose this overarching goal into a number of subsidiary transformations, each with their own business model. They will also have to consider the influence of customers, actors in the transformation process, owners of systems and their individual perspectives on the situation and the environmental constraints. However, in this paper, the focus is on the real-world situation of concern - the creation of TEP's overarching business model - and, in particular, the identification of potential opportunities for value generation.

\section{Methodology for identifying potential opportunities for value generation}

The methodology involves, for a given infrastructure development, a systematic search of Internet-based literature to identify value opportunities and is outlined in Figure 4. Business models describe how organisations - commercial or otherwise - create and capture value (Zott and Amit, 2010). Although a business model generally has 'to work' in economic terms, both the value generated (the multiple forms of value that any one infrastructure development might realise (Rogers, 2018)) and investments made (cf. the five capitals model referred to earlier (Porritt, 2005)) can, and typically will, extend beyond the economic sphere.

Step 1 of the methodology involves selecting the search terms and starts by defining in no more than two or three words the 'business' - that is, succinctly describing the infrastructure and its 


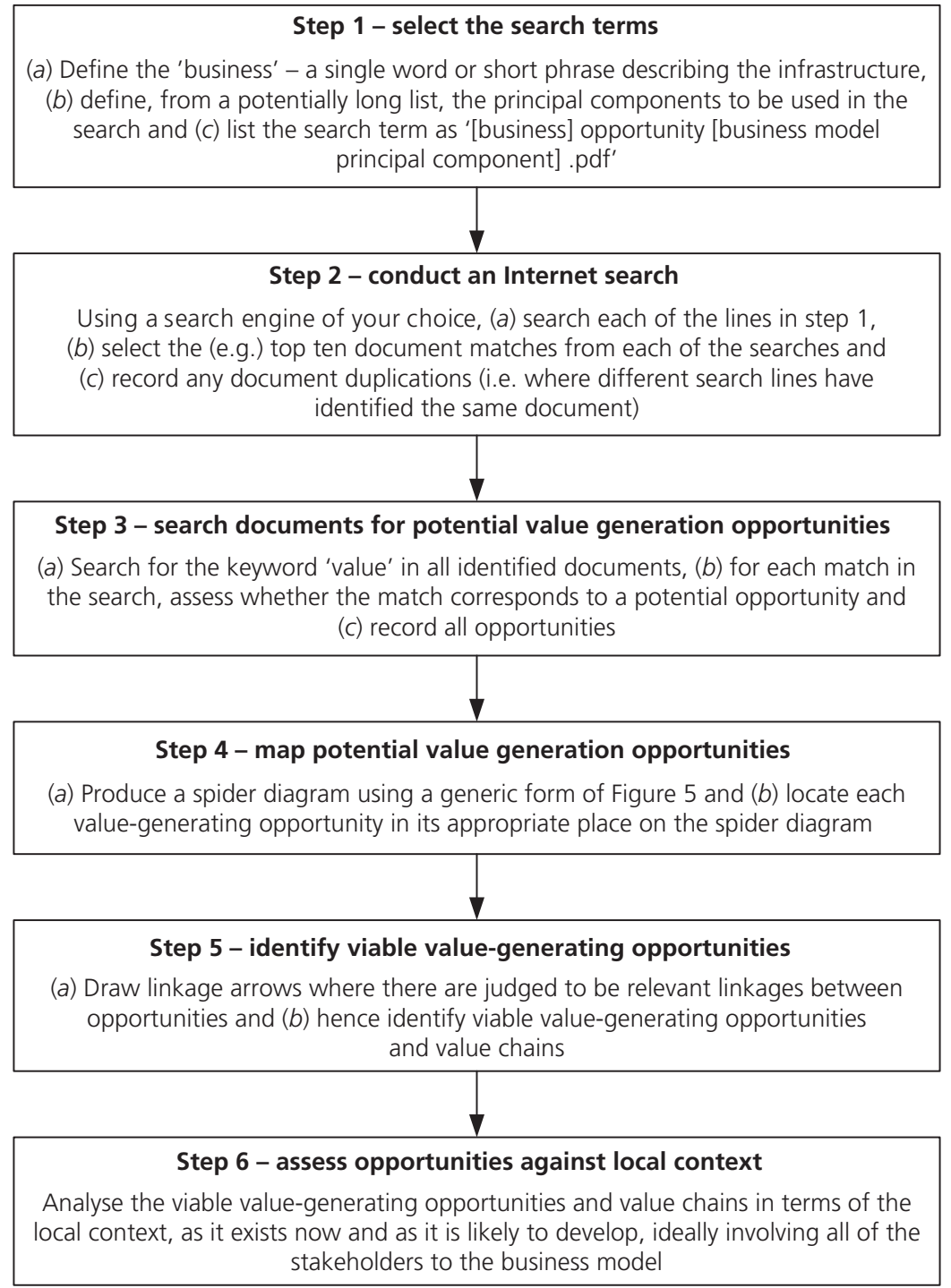

Figure 4. Methodology for identifying value generating opportunities for an infrastructure development

system of operation in question (whether this results from a new development or a substantial change to something pre-existing). Since the purpose is the identification of opportunities from which value might arise, the term 'opportunity' is used in the search. The third term relates to the principal components of the business model - that is, those that are considered important to the service that is provided and to the context in which the infrastructure operates and for which the business model is being created, while the final term is '.pdf' to steer the search towards documents rather than websites. This means that several searches are conducted, one for each principal component.

For the TEP case study, 'energy centre' was chosen as the business description and 12 web searches were carried out. The 12 business model principal components were identified based on research by Morris et al. (2005) on a unified perspective to the whole topic of business model creation. Morris et al.'s (2005) work synthesised the existing business model literature and drew conclusions regarding a number of the core business model issues, such as definition, nature, structure and evolution. As part of this work, they identified a large number of business model components. Although it would have been possible to include all of them as search terms, it was considered that there were too many to make the methodology practical. Moreover, when applying engineering judgement to the particular infrastructure business and context, it became clear that the components could be condensed down into the 12 principal components shown in Table 1.

Each of the TEP web searches therefore employed a search term built up as follows: 'energy centre', 'opportunity', one of the business model principal components and '.pdf', as follows

- energy centre, opportunity, market, .pdf

- energy centre, opportunity, economic, .pdf 
Table 1. The authors' 12 business model principal components mapped to the business model components identified by Morris et al. (2005)

\begin{tabular}{|ll|}
\hline Authors' principal components & Morris et al.'s components \\
\hline Economic & Price \\
& Revenue \\
& Value \\
& Costs \\
& Investment \\
Market & Product \\
& Services \\
& Segmentation \\
Strategy & Distribution \\
& Business units \\
& Linkages \\
Technical & Mission \\
& Technology \\
Infrastructure \\
Governance & ICT \\
& Corporate \\
Culture & Transactional \\
& Legal \\
Social & Organisational characteristics \\
& Information flow \\
Environmental & Actors \\
Competition & Roles \\
& Stakeholder network \\
Reputation & Sustainability \\
Intellectual curiosity & Competition strategy \\
& Success factors \\
& Capabilities \\
Customer relationship & Competence \\
& Process \\
Innovation \\
\end{tabular}

- energy centre, opportunity, reputation, .pdf

- energy centre, opportunity, resilience, .pdf

- energy centre, opportunity, intellectual curiosity, .pdf

- energy centre, opportunity, technical, .pdf

- energy centre, opportunity, governance, .pdf

- energy centre, opportunity, culture, .pdf

- energy centre, opportunity, market, .pdf

- energy centre, opportunity, competition, .pdf

- energy centre, opportunity, environmental, .pdf

- energy centre, opportunity, social, .pdf.

The Internet search is then carried out (step 2). The choice of search engine is again down to the judgement of the user (Google was used for the TEP case study because of its wide availability), as is the number of documents selected for future scrutiny. Going through the process results in a 'feel' for what number is appropriate; the top ten documents from each search were selected for the TEP case study.

The documents returned from each of the searches are themselves then searched using the term 'value' to identify opportunities for value generation (step 3). The number of documents searched will depend on the time available and the results obtained - for example, a significant fall in the number of new opportunities emerging as the search progresses would be an indicator that the search can be curtailed.

Value opportunities identified in the documents are mapped (step 4) in a spider diagram, such as that shown in Figure 5, the principal 'legs' of which are the business model principal components (for TEP, the 12 listed in Table 1). Some subjectivity engineering judgement - is involved in assigning each value opportunity to one of the business model principal components. Once the diagram is complete, the highly creative and contextspecific process of identifying viable value-generating opportunities (step 5) can begin; this includes looking for links between value opportunities to create 'chains' of value. While these chains of value could likewise be generic, the opportunity for realising value is indeed highly context specific and the business model must reflect this (step 6). Ideally, this part of the methodology should involve all of the stakeholders to the business model (Rogers, 2017), and it is here where the tensions between stakeholder expectations are mitigated by trade-offs (Lombardi et al., 2011a; see later) through a process in which the stakeholders 'continually negotiate and re-negotiate with others their perceptions' (Checkland and Scholes, 1999; see above).

\section{Value generation opportunities for TEP}

The results of the search for value-generating opportunities associated with TEP are shown in Figure 5's 'spider diagram'. The amount of detail has had to be reduced in order to make the diagram legible: a small circle at the end of a branch indicates that in the full diagram, there are further branches beyond that point. The diagram also shows arrows that are intended to indicate some, but by no means all, potential links between different value generation opportunities. Linking opportunities together like this will be an important part of maximising opportunities to generate the value necessary to support new business models for the infrastructure business in general and particularly smart infrastructure where the opportunities are inherently greater. As an example, the arrows in Figure 5 suggest that the value a business might gain from improving its reputation (top left on the diagram), and the trust that this engenders among other stakeholders, has the potential to encourage and facilitate other value-generating opportunities associated with

- closer community engagement, providing, perhaps, a better understanding of what consumers are really looking for

- environmental benefits around improved energy efficiency, which although not shown on the diagram will feed back into and reinforce reputation

- government policy changes to promote the fuel flexibility that may be needed to meet highly differentiated consumer needs

- improved system resilience stemming from the energy security implicit in flexible fuel policy

- greater social involvement through local control assisted by improved trust and better community engagement 

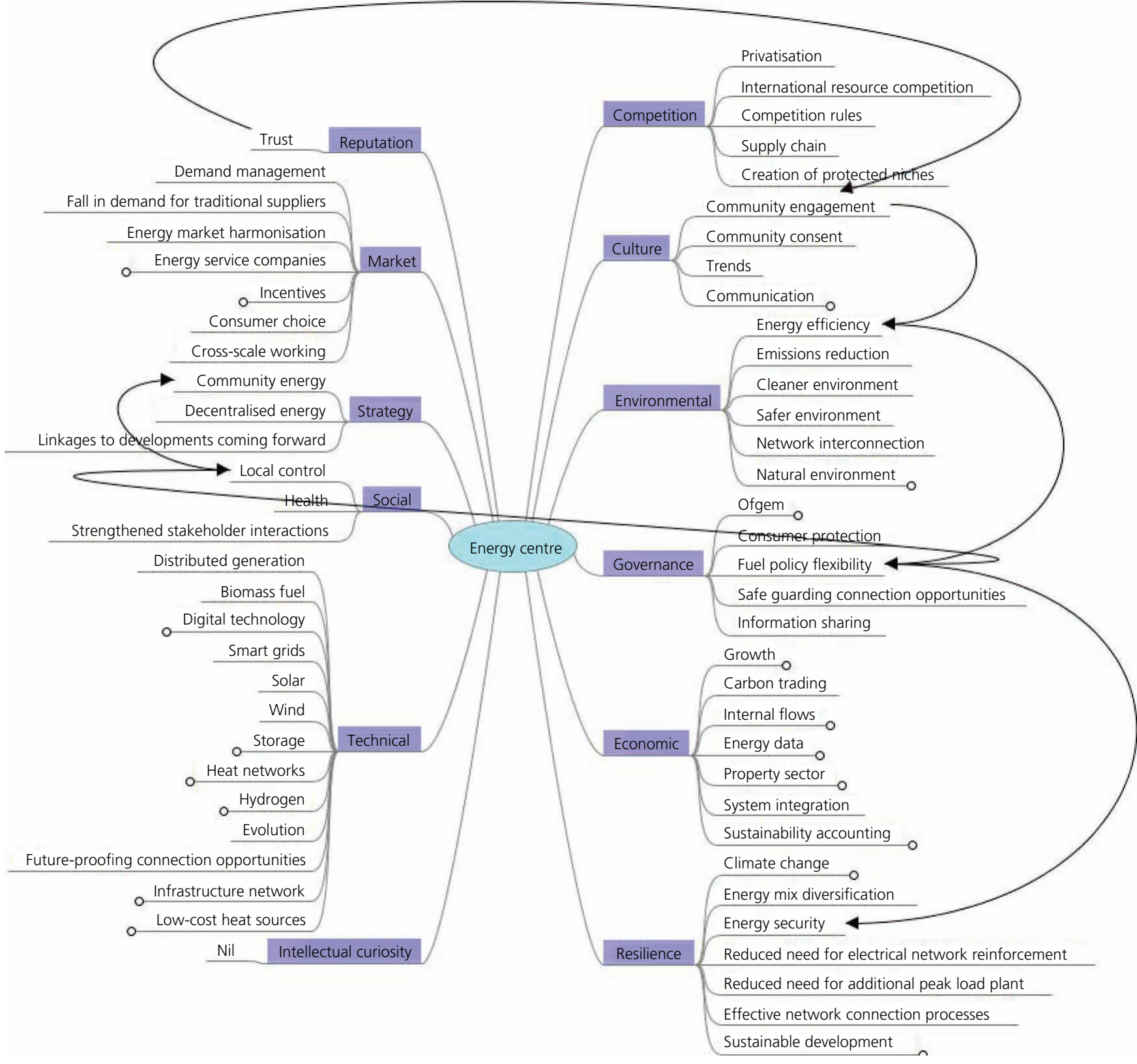

Figure 5. Spider diagram showing generic, potential value-generating opportunities associated with an energy centre such as TEP

- the suggestion that community energy initiatives might be an effective strategy for generating value opportunities.

It is important to note that the search results shown here are generic in that no special consideration has been given to the local context in which TEP is developing. The aim has been to demonstrate that this approach can identify potential opportunities for value generation and that by linking opportunities, the potential for value generation can be enhanced (step 5). However, further work would be required to establish to what extent those opportunities were valid in the specific context of TEP (step 6) for example, what social initiatives undertaken by $\mathrm{BCC}$ around health might there be - such as combating fuel poverty - that would provide an opportunity for TEP to create value?

\section{Discussion}

This paper proposes a novel methodology for identifying potential value-generating opportunities associated with an infrastructure business, and, as evidenced in this journal, the opportunities to enhance the value of infrastructure by making it 'smart' are considerable - for example, when considering bridge maintenance operations (Bennetts et al., 2018) or seeking to improve the capacity of transport infrastructure (Hillel et al., 2018). Essentially, the methodology starts with the business that is 
created by an infrastructure development - in this case TEP, which is referred to as an energy centre - and then goes through a structured search of Internet-based literature to identify potential value opportunities that can be used in the development of its business model. While the methodology requires an Internet search for .pdf documents, there are, of course, other information sources (e.g. the associated technical literature) and perspectives (from multiple potential stakeholders) that can be drawn on to identify where potential value lies, and, as is implicit in the soft systems approach, these should be pursued also to augment and enrich the final outcome. Indeed, many of these will become apparent as one applies the methodology and, as with all engineering practice, processes of reflection and iteration should be adopted.

When applying the methodology, it is important not to confuse 'business models' with 'business cases' (Rogers, 2018). A business model relates to the operations of what is hopefully an ongoing entity, whereas a business case relates to a project with a distinct beginning, middle and end, undertaken by an organisation to support a case for change, whether in terms of new construction, adaptation of existing infrastructure or its systems of operation or its governance (e.g. regulation, legislation, user behaviours). Both are important, are related and sit side by side, and both are needed before any decision on an infrastructure development can be made, yet they have distinct purposes. The business case is founded on an evidence base of practice and research, and 'the case needs to be made' - 'something should be done' - before a detailed consideration of alternative solutions to the problems being addressed is undertaken. The business model is the thing that elaborates the viability of the infrastructure business, showing that it will operate successfully and that the investment in it will have been warranted'. Clearly, the business case and business models need to be considered simultaneously and iteratively. In the context of this discussion, 'project finance', as used in this paper, refers to funding that will ultimately support TEP's overarching business model, rather than a stand-alone project.

The principal component terms (Table 1) used to search the Internet literature have been synthesised from business model research by Morris (professor of entrepreneurship at the University of Florida), which has been cited 741 times and as such provides a defensible framework. Reviewing the documents returned by each search is, however, problematic. The number of documents returned is often large - far too large to allow a detailed review of each one - and each of the documents themselves can be substantial. It rests with the reviewer, therefore, to review a sufficient number of documents to have confidence that no important opportunities have been missed. Heuristics need to be developed to assist with this - for example, as mentioned earlier, a significant fall in the number of new opportunities emerging as the search progresses might be taken as an indicator that the search can be curtailed. It has to be stressed that the opportunities identified by the search are generic and, as with step 6, additional input is required in step 3 to put a local perspective onto each of the opportunities. It is only having done this that a true picture of the viable opportunities will emerge.

Despite the need for engineering judgement to influence the process - leading to accusations of subjectivity - the methodology described provides a systematic way of identifying potential opportunities for value generation and is therefore robust. Clear statements of the assumptions made as the methodology is applied are needed to make any one application of the methodology transparent and hence repeatable. Importantly, since it is based on a search for, and review of, relevant Internetbased literature, it offers the chance to leverage the work of others around the infrastructure business under consideration; however, it is important to note that this approach should not be seen as completely mechanistic. It therefore provides an objective (based on the literature) and repeatable (two groups using this method should create similar results) way of identifying relatively quickly opportunities for value generation, without relying solely on the, perhaps, more subjective input of experts relating to a particular type of infrastructure. Indeed, experts of that type would be unlikely to have the broad view identified as desirable in the introduction to this paper. That said, the results of the exercise should ideally be used to prompt discussion with a broad range of stakeholders (in step 6), with the aim of identifying any glaring omissions and providing the context specific to the infrastructure development being considered. It is at this point that the trade-offs in conception and design (Lombardi et al., 2011a) can be considered, thereby refining and strengthening the business case, yet equally these considerations will influence how the infrastructure business operates and therefore the alternative business models that might be created in support of it.

Even when the business case for change has been successfully made and viable business models have been proposed and the best selected, there are two further requirements. The first of these, which is implicit in SSM, concerns alignment with all of the systems of governance within which the infrastructure business has to operate - the formal systems (legislation, regulation, codes and standards, taxation, etc.) and the informal systems (e.g. individual and societal attitudes, norms and behaviours) - if these are absent, or liable to change, then business models are at best vulnerable and at worst will fail (Rogers, 2018).

The second concerns the future: the value that can be placed on the longer-term attributes of sustainability (Lombardi et al., 2011b), resilience (Lombardi et al., 2012; Rogers et al., 2012a, $2012 \mathrm{~b}$ ) and, to a lesser degree, since the externalities can perhaps be better identified, liveability (Leach et al., 2016) and how resilient the business models themselves are likely to be - that is, how they are likely to be influenced by change (Rogers et al., 2012b). For this, it is recommended that scenario-based future foresight techniques are used in relation to the infrastructure business itself (GofS, 2018a) and the national, and where 
appropriate local, context in which it will operate (GofS, 2018b). The debate on the value of resilience will run, and personal (engineering judgement) and stakeholder perceptions are important here, whereas sustainability assessment frameworks can prove directly beneficial for identifying, and perhaps quantifying, the value that might be generated (e.g. Boyko et al., 2012; Pearce et al., 2012).

\section{Conclusions}

This paper has broken away from a narrow consideration of smart infrastructure based on data and communication technology, to take a much broader view in the context of business model creation. There is a great need for new and improved infrastructure in the UK, and this should be made smart if it is to deliver greater value, but funding is a problem - the government is looking for the private sector to provide up to half of the money required for its infrastructure pipeline, yet there remains a question mark over private investors' willingness to commit funding unless they can capture more of the wide range of value that infrastructure generates. New, alternative business models are required to give investors the confidence that they will capture the value they require to make investment worthwhile, and, to meet this need, a methodology is required to identify potentially valuegenerating opportunities.

This paper advocates using SSM as a framework within which to develop these new, alternative business models. An essential precursor to any consideration of a business model involves finding out about the existing systems and stakeholders, and it has been argued that part of this involves building an understanding of what opportunities there may be for the business to generate value. The paper proposes a methodology for identifying these opportunities based on a search of Internet-based literature using search terms that include the principal components of business models identified from the business model literature. The methodology has been illustrated using TEP as a case study.

The six-step methodology brings an objective and repeatable approach instead of having to rely solely on the potentially partial or siloed, and therefore incomplete, views of stakeholders and was successful in identifying a large number of potential valuegenerating opportunities for TEP. The results of the methodology, which treat the newly created, refurbished or upgraded infrastructure system as a business, are generic: once an opportunity for value creation has been identified, those employing the methodology must thereafter explore each opportunity in sufficient detail to understand whether it remains valid in the case of a specific business and geographical location. This is where it is important to introduce the views, and expertise, of all those who have a stake in the business - those operating it, governing it, being served by it or otherwise being influenced by it. Understanding how the business model can impact positively on the future (and hence realise future value), and in turn how it is likely to be impacted in the future so that it can be made resilient to change, provides additional important considerations.

\section{Acknowledgements}

This work on novel business models under the iBUILD programme has been funded by the UK Engineering and Physical Sciences Research Council and the Economic and Social Sciences Research Council (Grant Reference EP/K012398) and has been underpinned by the findings from the Liveable Cities programme grant (Grant Reference EP/J017698). The authors are grateful to the Vitech Corporation, Blacksburg, Virginia, USA, for providing an academic licence for CORE, their system modelling tool, together with technical support. The authors are equally grateful for the help received from Tyseley Energy Park Ltd, developers of TEP.

\section{REFERENCES}

Bartlett R (2017) Is Infrastructure a Public Good? No, Sort of, and What Role for the Public and Private Sectors. The Last Page Blog, Institute of Fiscal Studies and Democracy, University of Ottawa, ON, Canada. See http://www.ifsd.ca/en/blog/last-page-blog/infrastructure-publicgood (accessed 30/07/2018).

BCC (Birmingham City Council) (2012) Economic Zones: Investing in Birmingham. BCC Birmingham, UK.

Bennetts J, Webb GT, Vardanega PJ, Denton SR and Loudon N (2018) Using data to explore trends in bridge performance. Proceedings of the Institution of Civil Engineers - Smart Infrastructure and Construction 171(1): 14-28, https://doi.org/10.1680/jsmic.17.00022.

Boyko CT, Gaterell MR, Barber ARG et al. (2012) Benchmarking sustainability in cities: the role of indicators and future scenarios. Global Environmental Change 22(1): 245-254, https://doi.org/10. 1016/j.gloenvcha.2011.10.004.

Burger S and Luke M (2016) Business Models for Distributed Energy Resources: a Review and Empirical Analysis. MIT Energy Initiative, Cambridge, MA, USA, MITEI-WP-2016-02.

Cavada M, Hunt DVL and Rogers CDF (2014) Smart cities: contradicting definitions and unclear measures. Proceedings of the 4th World Sustainability Forum. See https://sciforum.net/paper/view/conference/ 2454 (accessed 13/03/2018).

Cavada M, Hunt DVL and Rogers CDF (2016) Do smart cities realise their potential for lower $\mathrm{CO}_{2}$ emissions? Proceedings of the Institution of Civil Engineers - Engineering Sustainability 169(6): 243-252, https:// doi.org/10.1680/jensu.15.00032.

Checkland P and Scholes J (1999) Soft Systems Methodology in Action. Wiley, Hoboken, NJ, USA.

Dawson R (2013) Bridges n'That: an Infrastructure Definition for iBUILD. i-Build, Newcastle, UK, Briefing Note 1. See https://research.ncl.ac.uk/ media/sites/researchwebsites/ibuild/BP1\%20-\%20An\%20infrastructure $\% 20$ definition\%20for\%20iBUILD.pdf (accessed 19/03/2018).

Dawson RJ, Walsh CL, Purnell P and Rogers CDF (2014) Briefing: Infrastructure business models, valuation and innovation for local delivery. Proceedings of the Institution of Civil Engineers Infrastructure Asset Management 1(3): 66-67, https://doi.org/10.1680/ iasma.14.00027.

Egyedi T and Mehos D (2012) Inverse Infrastructures: Disrupting Networks from Below. Edward Elgar, Cheltenham, UK.

EIB (European Investment Bank) (2011) The Guide to Guidance: How to Prepare, Procure and Deliver PPP Projects. European PPP Expertise Centre, Luxembourg, Luxembourg.

Energy Capital (2018) 21st Century Energy. Energy Capital, Birmingham, UK. See https://www.energycapital.org.uk/ (accessed 27/04/2018).

GBSLEP (Greater Birmingham and Solihull Local Enterprise Partnership) (2013) Delivering Growth: Strategic Framework. GBSLEP, Birmingham, UK.

GofS (Government Office for Science) (2018a) Future of Cities: Foresight for Cities. Foresight, GofS, London, UK. See http://www.gov.uk/ 
Developing alternative business models

for smart infrastructure: a UK case study

Bouch, Rogers, Powell and Horsfall government/publications/future-of-cities-foresight-for-cities (accessed 03/10/2018).

GofS (2018b) Future of Cities: UK Scenarios. Foresight, GofS, London, UK. See http://www.gov.uk/government/publications/future-of-citiesuk-scenarios (accessed 03/10/2018)

Hillel T, Elshafie MZEB and Jin Y (2018) Recreating passenger mode choicesets for transport simulation: a case study of London, UK. Proceedings of the Institution of Civil Engineers - Smart Infrastructure and Construction 171(1): 29-42, https://doi.org/10.1680/jsmic.17.00018.

HMT (Her Majesty's Treasury) (2010) National Infrastructure Plan 2010. HMT and Infrastructure UK, London, UK.

IEC (International Electrotechnical Commission) (2014) Orchestrating Infrastructure for Sustainable Smart Cities. IEC, Geneva, Switzerland.

IPA (Infrastructure and Projects Authority) (2016) National Infrastructure Delivery Plan 2016-2021. IPA, London, UK.

KPMG (2017) Ten Emerging Trends in 2017: Trends That Will Change the World of Infrastructure. KPMG, Zurich, Switzerland, Publication Number 133954-G.

Leach JM, Braithwaite PA, Lee SE et al. (2016) Measuring urban sustainability and liveability performance: the City Analysis Methodology (CAM). International Journal of Complexity in Applied Science and Technology 1(1): 86-106, https://doi.org/10.1504/IJCAST. 2016.081296

Lombardi DR, Caserio M, Donovan R et al. (2011a) Elucidating sustainability sequencing, tensions and tradeoffs in development decision-making. Environment and Planning B: Planning and Design 38(6): 1105-1121, https://doi.org/10.1068/b36161.

Lombardi DR, Porter EJ, Barber ARG and Rogers CDF (2011b) Conceptualising sustainability in UK urban regeneration: a discursive formation. Urban Studies 48(2): 273-296, https://doi.org/10.1177/ 0042098009360690

Lombardi DR, Leach JM, Rogers CDFthe Urban Futures Team (2012) Designing Resilient Cities: a Guide to Good Practice. IHS BRE Press, Bracknell, UK.

Magretta J (2002) Why business models matter. In Harvard Business Review, May, pp. 3-8.

Midlands Engine (2018) We Are the Midlands Engine. Midlands Engine, Nottingham, UK. See https://www.midlandsengine.org/ (accessed 27/04/2018).

Morris M, Schindehutte M and Allen J (2005) The entrepreneurs business model: toward a unified perspective. Journal of Business Research 58(6): 726-735, https://doi.org/10.1016/j.jbusres.2003.11.001.

OECD (Organisation for Economic Co-operation and Development) (2014) Private Financing and Governmental Support to Promote Long-term Investments in Infrastructure. OECD, Paris, France.
Pearce OJD, Murry NJA and Broyd TW (2012) Halstar: systems engineering for sustainable development. Proceedings of the Institution of Civil Engineers - Engineering Sustainability 165(2): 129-140, https://doi.org/10.1680/ensu.9.00064.

Porritt J (2005) Capitalism as if the World Matters. Earthscan, London, UK.

Randles S and Laasch O (2016) Theorising the normative business model. Organization \& Environment 29(1): 53-73, https://doi.org/10.1177/ 1086026615592934.

Rogers CDF (2017) The value of foresight and scenarios in engineering liveable future cities. In Retrofitting Cities for Tomorrow's World (Eames M, Dixon T, Hunt M and Lannon S (eds)). Wiley Blackwell, Chichester, UK, pp. 139-152.

Rogers CDF (2018) Engineering future liveable, resilient, sustainable cities using foresight. Proceedings of the Institution of Civil Engineers Civil Engineering 171(6): 3-9, https://doi.org/10.1680/jcien.17.00031.

Rogers CDF, Bouch CJ, Williams S et al. (2012a) Resistance and resilience - paradigms for critical local infrastructure. Proceedings of the Institution of Civil Engineers - Municipal Engineer 165(2): 73-84, http://doi.org/10.1680/muen.11.00030.

Rogers CDF, Lombardi DR, Leach JM and Cooper RFD (2012b) The urban futures methodology applied to urban regeneration. Proceedings of the Institution of Civil Engineers - Engineering Sustainability 165(1): 5-20, http://doi.org/10.1680/ensu.2012.165.1.5.

Siemens (2018) Distributed Energy Systems: Multiple Participants for Multiple Benefits. Siemens, Munich, Germany. See https://www. siemens.com/global/en/home/company/topic-areas/sustainable-energy/ local-energy.html (accessed 19/03/2018).

University of Lancaster (2018) Professor Peter Checkland, Emeritus Professor, Profile. University of Lancaster, Lancaster, UK. See http:// www.lancaster.ac.uk/lums/people/peter-checkland (accessed 25/04/ 2018).

UNCSTD (UN Commission on Science and Technology for Development) (2016) Smart Cities and Infrastructure: Report of the Secretarygeneral. UNCSTD, Geneva, Switzerland.

UoB (University of Birmingham) (2018) University of Birmingham Invests in Tyseley Energy Park. UoB, Birmingham, UK. See https://www. birmingham.ac.uk/news/latest/2018/05/university-birmingham-tyseleyenergy-park.aspx (accessed 31/08/2018).

WHHL (Webster and Horsfall (Holdings) Ltd) (2018) Tyseley Energy Park. WHHL, Birmingham, UK. See https://www.whhl.co.uk/tyseleyenergy-park/ (accessed 11/05/ 2018).

Zott C and Amit R (2010) Designing your future business model: an activity system perspective. Long Range Planning 43(2-3): 216-226, http://doi.org/10.1016/j.lrp.2009.07.004.

\section{How can you contribute?}

To discuss this paper, please email up to 500 words to the editor at journals@ice.org.uk. Your contribution will be forwarded to the author(s) for a reply and, if considered appropriate by the editorial board, it will be published as discussion in a future issue of the journal.

Proceedings journals rely entirely on contributions from the civil engineering profession (and allied disciplines). Information about how to submit your paper online is available at www.icevirtuallibrary.com/page/authors, where you will also find detailed author guidelines. 